International Journal of Learning Management Systems

@ 2014 NSP

Natural Sciences Publishing Cor.

http://dx.doi.org/10.12785/ijlms/020203

\title{
My Engineering Students Neglect Their Statistics Course Homework: What Policies Should Introduce to Motivate Them to Do Their Home Work?
}

\author{
Eman Khorsheed* \\ University of Bahrain, Kingdom of Bahrain. \\ *Email: ekhorsheed@uob.edu.bh
}

Received: 3 Oct. 2013; Revised: 2 Nov. 2013; Accepted: 7 Dec. 2013

\begin{abstract}
This study investigates the relationship between undergraduate engineering students' attitudes toward statistics, attitudes toward homework, and rate of homework completion when enrolled in a statistics course. The Attitude Toward Statistics Scale (ATS) and an Attitude Toward Homework Opinionnaire were used. ATS reliability was evaluated using the internal-consistency method. Hypotheses examining differences in attitudes between two groups of students and the effect of their attitudes on rate of homework completion were addressed using statistical tests and ANOVA. The study also focuses on the impact of introducing a new homework policy on students' motivation to do homework in frame of an action research. Results suggest that students are more willing to do homework when the adopted homework policy fulfills most of their relevant high-level needs including ease of communication with their instructor.
\end{abstract}

Keywords: Statistics education research; Attitude Toward Statistics Survey; Attitude Toward Homework Opinionnaire; Action Research; Reliability; computer-mediated communication.

\section{Introduction and Background}

Statistics was seen as an overwhelming learning experience by many students enrolled in its courses. Onwuegbuzie and Daley (1999) found that students enrolled in a compulsory introductory statistics course often view the course as an overwhelming learning and survival task that cause a great deal of stress. Roberts and Saxe (1982) research shows that students' attitudes and their achievement are related. Gal, Ginsburg and Scau (1997) stressed that students' attitudes deserve attention for their role in influencing: (1) the teaching/learning process; (2) students' statistical behavior outside the classroom.

Griffith, Adams, Gu, Hart and Nichols-Whitehead (2012) stated: "Teaching statistics may be regarded as a complicated endeavor because many factors in addition to the pedagogical approach must be taken into consideration. Thus, there is ample evidence that among the many factors to take into consideration when teaching a course in statistics, attitudes toward the course should certainly not be ignored." Attitudes toward statistics is defined by Emmioğlu and CapaAydin (2012) as a multidimensional construct representing students' learned predispositions to 
respond positively or negatively to statistics. The importance of attitudes in statistical education has been discussed also by many authors such as Ramirez, Schau and Emmioğlu (2012).

A first step in assessing the students' attitudes towards statistics is to develop and evaluate practical tools; work that has already been initiated by a number of researchers (e.g., Roberts \& Bilderback 1980; Wise 1985; Schau, Stevens, Dauphinee \& Del Vecchio 1995).

Most researchers have examined the relationships between attitudes toward statistics and statistics course achievement by correlating attitude and achievement (Sorge \& Schau 2002; Emmioğlu et al., 2012). These authors have reported significant relationships. For example, Ramirez et al., (2012) stated:"More positive attitudes were associated with higher achievement in students' statistics course." Unfortunately, only few studies investigated the relationships among attitudes about homework and amount of homework assigned and completed (Cooper, H., Lindsey, J., Nye, B., \& Greathouse, S., 1998).

It is generally believed that in order for most engineering students to learn concepts that are taught in problem oriented courses, they must work problems that illustrate those concepts (Trussell, 2003). Few students like to do homework and seem naturally enthusiastic about it, but many need or expect their instructors to inspire, challenge, and stimulate them: "Effective learning in the classroom depends on the teacher's ability ... to maintain the interest that brought students to the course in the first place" (Ericksen, 1978).

A great deal of research evidence demonstrated that benefits from homework can include immediate achievement and learning by practice (Cooper, 1994). Also, (Cooper et al., 1998) stated that academic achievement is positively related to homework. On standardized tests (Cooper, 2001) found that a typical homework completing high school student will outperform students who do not do homework by $69 \%$. Research shows homework can raise a student's G.P.A. by one-half point for 30 extra minutes of homework per night (Marzano, R., Pickering, D., \& Pollock, J., 2001). Also homework was found to provide not only short term academic benefits but also long term benefits such as "encouraged learning in leisure time, an improved attitude towards school, and better study skills and habits", including the value of effort and the ability to cope with mistakes and difficulty (Bempechat, 2004). In addition to some nonacademic benefits including "greater self direction, self discipline, time organization, inquisitiveness, independent problem solving" (Cooper, 1994).

As an instructor at University of Bahrain, I have struggled to know why more than $80 \%$ of my engineering students involved in a compulsory introductory statistics course neglected their homework assignments. I wondered whether they are really aware of what homework is and why is it assigned? I wanted to understand more about their perceptions of homework and to find out what are their needs.

Engineering students are rarely studied in regard to statistics education; yet they are an interesting group because of their strong backgrounds in mathematics (Sorge et al., 2002).

I feel strongly that one important role of my career, as an instructor, is to investigate possible factors that may hinder many students from turning in homework. Because motivation is a necessary ingredient for learning (Biehler \& Snowman, 1986), it is also very important to 
introduce different policies that may motivate student to regularly complete his/her homework. This may be achieved through reflective practices.

The connection between teaching and reflection originated with Dewey (1933), who thought of reflection action as a form of problem solving that chained several ideas together by linking each idea with its predecessor to resolve an issue. Action research involves a self-reflective cycle of identifying a problem, planning a change, acting and observing the processes and consequences, and then re-planning, and so forth. Kemmis (in Hopkins, 1985) provides a diagrammatic representation of an action research protocol (Figure 1), describing each cycle in four steps: plan, action, observe, and reflect.

This study proposed to assess students' attitudes toward statistics, their attitudes toward homework, and the relationship between the students' attitudes and portion of homework turned in. Action research was applied in this work to determine the extent to which the implementation of some motivational strategies, through cycles of reflective practices, might influence homework completion and students mastery level of the content.

CYCLE 1

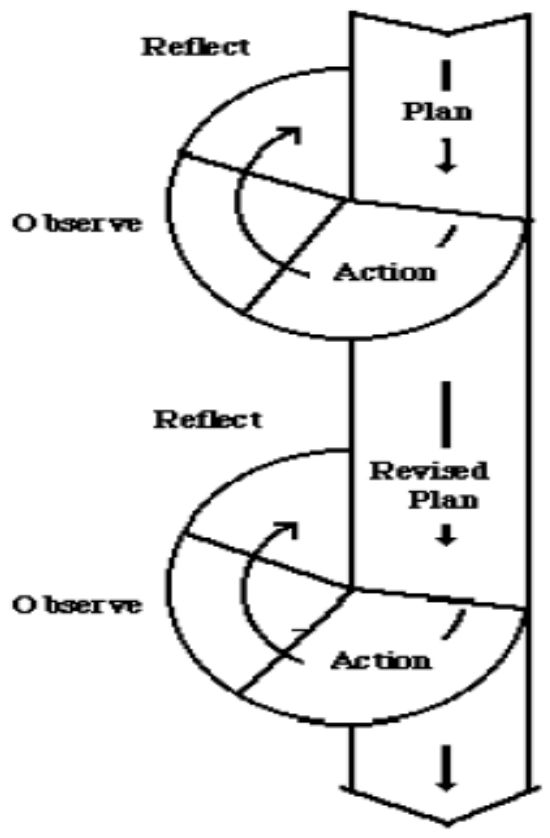

Figure 1. Kemmis action research protocol (cited in Hopkins, 1985)

\section{Methodology}

\section{Participant}

Participants of the present study are 50 engineering students enrolled in an introductory undergraduate statistics course (STAT 273). These students were registered in two different morning sections and consecutive academic semesters at the UoB. I shall refer to the first section 
as Group A (21 students) and the second as Group B (29 students). I was the instructor of both groups.

There were 32 females and 18 males in the sample. $90 \%$ of the students had not taken a college statistics course prior to the current one. The remaining $10 \%$ of the students were repeating the course to replace poor or failing grades. All participants had previously taken the prerequisite math course (MATHS 101) prior to the current statistics course. No students reported taking more than three math courses prior to this course. For all students, the statistics course was a requirement for their programs of study.

All participants were between the ages of 19 and 21 years old. The study started few weeks after classes began to allow the students some time to be familiar with the instructor and the course. All students were briefed about the nature of the study and were informed that participation was voluntary. The students were also assured that their responses would be treated with confidentially. All students participated in the study and agreed to sign in a consent form confirming that.

\section{Design}

This study has two lines of related research. The first line of research assesses both groups A and B students' attitudes toward statistics and toward homework, and examines the possible differences between the corresponding attitudes. It also explores the potential relationship between the students' attitudes toward statistics and their attitudes toward homework, and the effect of this relationship on the students' rate of homework completion.

The action research in the second line of this work explores through four self-reflection cycles, the effect of changing the instructor's homework policy on improving the students' attitudes and their level of motivation to do and complete their homework regularly.

\section{Instrumentation and Procedure}

To collect data related with my students' attitudes toward statistics the Attitude Toward Statistics Scale (ATS; Wise 1985) was administrated twice during the $4^{\text {th }}$ week of each semester: one administration for each group. The ATS is a 29-item, Likert-type scale with five response possibilities ranging from "strongly disagree" (score 1) to "strongly agree" (score 5). The ATS questionnaire includes both negatively and positively formulated items. A higher score on the ATS indicates a more positive attitude toward statistics. ATS has two subscales: (1) 9-items COURSE subscale, measuring attitudes toward the course students are enrolled in, and (2) 20items FIELD subscale, measuring attitudes toward the use of statistics in their fields of specialization.

Instructions on completing the ATS had been given to the participants together with an Arabic version translated by Aldogan and Aseeri (2003) to help them interpret the context more easily and clearly.

The attitudes toward homework were studied by several researchers. Cooper et al. (1998) examined relationships between the time spent on homework, the portion of homework completed, and student's attitudes toward homework. These researchers developed a five items 
questionnaire including a question about whether a student liked homework or not. They found that students' attitudes toward homework are positively correlated with their reports of the portion of homework they completed and the time they spent on homework. Xu (2005) examined the same above relationships on a sample of high school students and reached to the same conclusion. The latter author posed a five items scale related to affective reactions toward homework (e.g., "doing homework helps you learn study skills"). Possible response statements for each item were strongly disagree (scored 1), disagree (scored 2), agree (scored 3), and strongly agree (scored 4).

In the light of the above authors' surveys, I developed a five items Likert-type opinionnaire by pulling three items from Xu (2005) questionnaire and adding two items from my side, with the same four possible responses, to measure my students' attitudes toward homework. This opinionnaire is called "ATH" in this study.

Items of ATH are:

1- Doing homework helps you learn study skills.

2- Doing homework makes your life difficult.

3- Doing homework wastes your time.

4- Doing homework helps you develop good discipline.

5- Doing homework helps you learn to work independently.

Items 1, 4, and 5 of $\mathrm{Xu}$ (2005) are related to doing homework for self-regulation. The remaining items are negatively worded and so responses were reversed.

Both the ATS scale and the ATH opinionnaire were conducted during regular class time so that I could give a clear explanation to students and clarify all queries raised. In addition, 100\% return rate could be ensured.

\section{Hypotheses}

In this study, three hypotheses were tested at 0.05 level of significance. They are:

1- There will be no significant difference in attitudes toward statistics between students in group A and students in group B.

2- There will be no significant difference in attitudes toward homework between students in group A and students in group B.

3- There is no significant correlation between the students' attitudes toward statistics and their attitudes toward homework.

\section{Data Analysis}

To statistically analyze the ATS and the ATH data the scores obtained were fed to the statistical software $R$. The reliability of both instruments was evaluated using the method of internal consistency (Cronbach's alpha). The mean scores for ATH and each subscale of ATS, namely: COURSE and FIELD, and the corresponding standard deviations were also calculated.

\section{Results}


The internal consistency in the form of Cronbach's alpha estimates, mean scores, and standard deviations of the subscale scores for the ATS of both groups A and B students are shown in Table 1.

Table 1. Reliability, descriptive statistics, and effects of groups on students' attitudes toward statistics for ATS scale data.

\begin{tabular}{|c||c||c||c|c||c||}
\hline ATS & & Group A & Group B & F-statistics & p-value \\
\hline \hline Subscale & Total number & 21 & 29 & & \\
\hline \multirow{3}{*}{ COURSE } & Alpha & 0.82 & 0.77 & \multirow{2}{*}{0.0135} & \multirow{2}{*}{1.00} \\
& Mean & 30.6 & 30.5 & & \\
& Standard & 6.6 & 5.9 & & \multirow{2}{*}{0.99} \\
& deviation & & & & \\
\hline \hline \multirow{3}{*}{ FIELD } & Alpha & 0.89 & 0.78 & \multirow{2}{*}{0.1004} & \\
& Mean & 66 & 61 & & \\
& Standard & 12 & 8.4 & & \\
& deviation & & & & \\
\hline
\end{tabular}

Although the COURSE and FIELD Cronbach's alpha estimates for Group B are relatively high $(\alpha>0.7)$ for both subscales, they are lower than the corresponding estimates for Group A. This indicates that the data set of the latter group is internally more consistent than that of group B. However, the results of both groups in our study are confirming the high reliability estimates of ATS scale reported in several other studies (Kottke 2000; Rhoads \& Hubele 2000; Vanhoof et al, 2006). Also, they are in line with those observations of Nolan, Beran \& Hecker (2012) who presented a systematic review of validity and reliability of student's attitudes toward statistics underlying available survey tools and found the internal consistency for ATS subscales were generally excellent ( $\alpha \geq 0.75$ ).

The difference between the COURSE subscale mean scores of both groups is negligible. A mean score of about 30.5 is indicating a rather positive attitude toward the statistics course (neutral score is 27). With regards to students' attitude toward the FIELD subscale, both the mean score of Group A and its standard deviation are higher than those of B. These results revealed that students of group A had higher positive attitudes toward the field statistics than those of group B (neutral score is 60). Although both subscale means are positive, if compared to other studies, e.g., Mvududu (2003) with Course and Field mean estimates of 34.9 and 79.5, respectively, my students' scores are clearly lower, especially those of the Field subscale. This obviously reveals that my students had, in general, positive but weak attitudes toward both the COURSE and the FIELD of statistics.

From the results above, it is found that there were some differences among the two samples' attitude scores. To test whether these differences are significant or they are only attributed to chance, it was decided to follow-up one-way ANOVA computations on mean subscale scores. Hypothesis 1 was designed to investigate the potential differences in attitudes 
toward statistics between group A and group B students. ANOVA test was carried at $\alpha=0.05$ level of significance. The $F$ values and $p$ values for hypothesis 1 are shown in Table 1 . These results suggested that hypothesis 1 cannot be rejected, i.e., students of the two groups A and B have the same positively weak attitudes toward statistics on both levels: COURSE and FIELD.

The ATH opinionnaire alpha estimates for both groups A and B are relatively high and almost equal, with an average of 0.72. Group A has a ATH mean score of 3.01 and a standard deviation of 0.37 . The corresponding values of Group B are 2.98 and 0.35 , respectively. These results indicate that both groups $\mathrm{A}$ and $\mathrm{B}$ tended to agree on self-regulation items and disagree on the remainder reversed items of the ATH. The difference between the average scores of both groups A and B is not significant in a $t$-test at $(t=0.269, \alpha=0.05)$, and hence hypothesis 2 cannot be rejected. No scores less than 2 were obtained for any item of ATH. The ATH opinionnaire results are summarized in Table 2 and Figure 2.

Table 2. Descriptive statistics for ATH scale data.

\begin{tabular}{|c|c|c|c|}
\hline Item & Mean score & Standard deviation & $\begin{array}{c}\text { Percentage } \\
\text { (score 2-disagree) }\end{array}$ \\
\hline 1 & 3.4 & 0.5 & $0 \%$ \\
\hline 2 & 2.9 & 0.7 & $28 \%$ \\
\hline 3 & 2.9 & 0.7 & $28 \%$ \\
\hline 4 & 3.1 & 0.36 & $0 \%$ \\
\hline 5 & 3.3 & 0.46 & $0 \%$ \\
\hline
\end{tabular}

Although the results mentioned above indicate relatively moderate positive attitudes toward homework, items 2 and 3 reveal that more than $25 \%$ of my students believe homework makes life difficult, and is time wasting. These results allude to a possible linkage between the students' attitudes toward statistics and their attitudes toward homework. To examine the potential relationship between these types of attitudes (hypothesis 3), a correlation analysis was generated on both sets of data: ATS and ATH. Mean scores of both groups of students were combined and the analysis showed that attitudes toward homework were significantly related to students' attitude toward the course $(r=0.65)$ and 


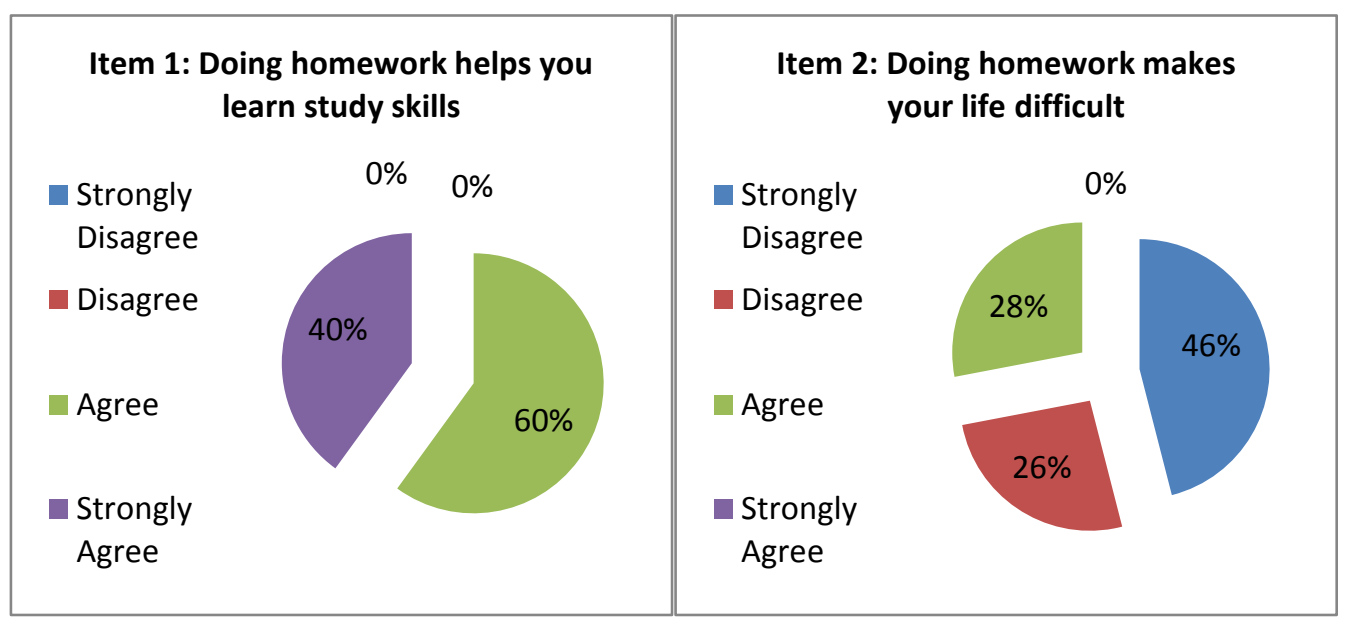

\begin{tabular}{|c|c|c|c|}
\hline \multicolumn{2}{|c|}{$\begin{array}{c}\text { Item 3: Doing homework wastes } \\
\text { your time }\end{array}$} & \multicolumn{2}{|c|}{$\begin{array}{l}\text { Item 4: Doing homework helps you } \\
\text { develop good discipline }\end{array}$} \\
\hline $\begin{array}{l}\text { Strongly } \\
\text { Disagree }\end{array}$ & $0 \%$ & $\begin{array}{l}\text { Strongly } \\
\text { Disagree }\end{array}$ & $10 \% 0 \% \quad 0 \%$ \\
\hline Disagree & $28 \%$ & Disagree & \\
\hline Agree & & Agree & \\
\hline $\begin{array}{l}\text { Strongly } \\
\text { Agree }\end{array}$ & & $\begin{array}{l}\text { Strongly } \\
\text { Agree }\end{array}$ & \\
\hline
\end{tabular}

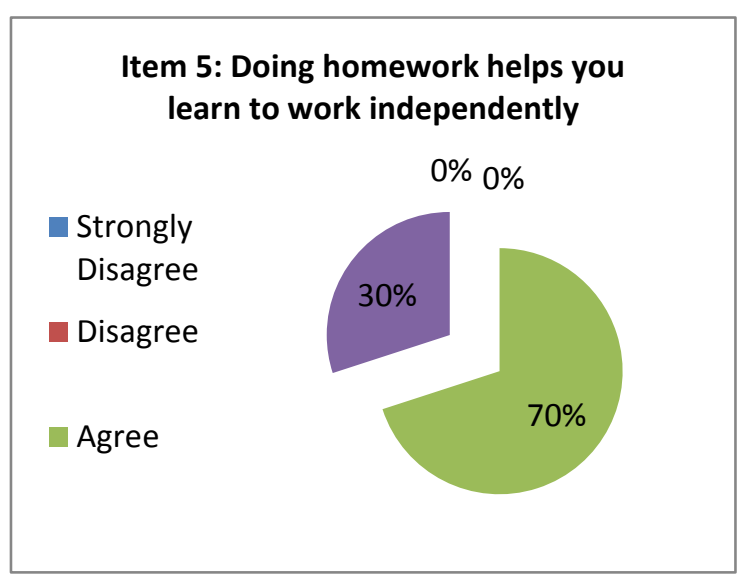

Figure 2. ATH opinionnaire responses 
toward the field $(r=0.6)$. These magnitudes of correlation coefficients indicate positive relatively strong relationships. As a result, students with high positive attitudes toward Statistics are found to have a higher portion of homework completed. My results are in line with those of Cooper et al., (1998) and Xu (2005) mentioned earlier in this study.

\section{Action Research On Homework Policy}

\section{Introduction}

The assessment of students' attitudes toward statistics is an important tool for predicting academic performance (Nolan et al., 2012). The ATS and ATH responses observed, in line one of this study, revealed that many of my students' had positive but weak attitudes toward the statistics field, course and related homework. This may justify the low rate of homework completion recorded. However, these responses did not provide information about possible causal factors and sources of the expressed attitudes. This is because the ATS have not been designed to provide diagnostic information that can point to particular issues of concern to individual students (Gal \& Ginsburg, 1994), and the ATH items were either related to affective reactions toward homework (e.g., item 2) or perceived purposes for homework (e.g., item 1).

Nolan et al., (2012) stated "Improving students' attitudes through educational interventions may increase confidence in their ability to understand statistical information and problem-solve using statistics beyond the classroom". Therefore, to increase my students' homework completion rates, I decided to focus on the issue of the possible main causal factors behind their attitudes. I thought that these factors have negatively influenced their motivation and interest in completing their homework. I believed it was essential to minimize the effect of these factors and hence improve students' engagement in the coursework through the homework policies to be adopted.

My original starting point in my investigation was to question the way I was handling homework to my students. I have used to assign them homework on a regular basis, for example, after every session or few related sessions. All homework problems were selected from the textbook and listed on the syllabus distributed early in the semester. Each assignment consists of 20 to 40 problems on the covered material. Some of these problems are similar and were selected to enhance students' practice learning specific skills, i.e., a type of repetitive homework.

I also believed that students are more engaged in learning when they are active and have some choice and control over the learning process, as found by Anderman and Midgley (1998). Therefore, I have always given my students the freedom to choose from the various suggested problems, but also advised them to solve as many problems as possible. I regularly allow appropriate class time or sessions (tutorials) to discuss the homework, especially those problems which students struggled with or could not solve. Students are expected to check their own homework by comparing their final answers with those included in their textbooks, or by the solutions we derive together during tutorial sessions. Marks of the course are distributed only on tests and final exam. I do not collect nor grade homework. To monitor rates of homework completion, I would ask my students at the beginning of each tutorial session: "who have solved the problems", and would identify and count those who were involved. I would also ask "what difficulties did you faced and where" to capture those problems that most students struggled with and then solve them together. 
The policy described above is my usual homework policy I used to follow in most of my classrooms. In this research, this homework policy will be called "homework policy 1".

I have followed policy 1 with my students of Group B during the first academic semester through six homework assignments. $100 \%$ of my students agreed that doing homework helps in learning study skills and working independently, see items 1 and 5 of the ATH opinionnaire in Figure 2. Therefore, I thought by implementing this policy my students will be self-directed and will show some self-motivation, especially that I clarified, from the beginning of the term, what is expected from them to do for a tutorial session, and what they will gain from practicing the desired taught skills. I thought that my students were adequately learning what I was trying to teach them, but through close observation of their portion of homework completed and their midterm scores, I have faced with disappointing evidence to the contrary. Students have not learned as much as or as well as was expected. There was clear evidence that homework policy 1 did not work well for many students of group B.

I was puzzled by my students' attitudes towards the course, field and homework. I wanted to know exactly why they do not do their homework, what their needs are, and what types of support or educational experiences might be useful for them.

Harvey et al. (1985), cited in Mvududu (2003), found that while attitude toward the course was significantly related to performance, attitude toward the field, generally, was not related to performance. So I thought this might be a good start. To identify the causal factors of the problem, I presented my students with a single-item questionnaire that I prepared in which they would have to answer, without writing their names, this question: WHY I DID NOT DO MY STATISTICS COURSE HOMEWORK? Students were shocked by the question but got immediately involved. The form was distributed and collected in one of the tutorial sessions. Students seemed to answer the question honestly. Some responses were:

1. Lack of time

2. Proper time to do homework is 2 days before the exams

3. Some problems are difficult or long

4. Forgot or lazy

5. Many problems for each homework. For what?

6. Not understand the previous material.

7. It is better to study for a test or midterm than doing an ungraded homework in a specific time.

Herzberg (1966) developed the Motivator-Hygiene Theory. This theory is closely related to Maslow's Hierarchy of Needs theory (1943) but relates more specifically to how individuals are motivated in the workplace. Based on his research, Herzberg argued that meeting the lower-level needs (hygiene factors, e.g., safe working conditions and security) of individuals would not motivate them to exert effort, but would only prevent them from being dissatisfied. Only if highlevel needs (motivators) were met would individuals be motivated.

Following the Motivator-Hygiene theory, I developed a new homework policy that may motivate students to do their homework by capitalizing on their high-level needs perceived from their responses to the single item questionnaire. The idea of this policy was based on changing the extrinsic nature of the homework and little of its intrinsic content (type), way of handing it, 
assistance type and rate, communication medium, and assessment policy. In this research, I will refer to this policy as homework policy 2 . To build-up the new policy, I followed four strategies through four cycles of investigation, as detailed below.

The plan in this research was to observe rates of homework return, based on types of homework policies implemented through cycles of reflective practices followed with students in both groups $\mathrm{A}$ and $\mathrm{B}$.

\section{Cycles of Action Research}

\section{Cycle 1:}

The strategy of this cycle was designed to meet the following students' high-level needs:

1- not to be overloaded;

2- to have moderate level of homework with enough time to complete;

3- to be directed for proper selection of homework problems.

Action: change type and way of handing homework

My students seemed to be overwhelmed and discouraged by the type of repetitive homework I used to assign them by policy 1 . They found the task very time consuming and boring, so many decided not to do it. Keys, Harris, \& Fernandes (1997) revealed that the relationship between homework and achievement is curvilinear, so that a lot or very little time spent on homework is less productive. Therefore, I decided to make my homework assignments more "efficient", and more "realistic", by handing my students "concrete" and "directive" WORKSHEETS of which each consists of only 6-8 problems. The chosen problems were neither very easy nor very difficult, and were carefully selected from the textbook to help students practice all the new taught skills. I assigned homework every tutorial session, and then allow a reasonable amount of time for homework to be completed (1 week). On the due day session, I would only quickly check for homework completion (no credit), solve together those problems which students struggled with, and then hand out my students the next worksheet before I leave the classroom.

Students of group B were handed two worksheets using this strategy, whereas those of group A were handed one worksheet. The students were slightly motivated and although their homework completion rate has risen, it remained unsatisfactory. See Table 4.

\section{Cycle 2:}

The strategy of this cycle aims to satisfy the following students' high-level need:

1- to overcome homework challenges.

Action: provide supportive instructions and virtual office hours

Students enrolled in this course often complain that they did not understand the assigned questions, either because of language problems, or lack of skills, or even both. According to Ostler (1997), experimental evidence shows that improving students' ability to comprehend the text increases their homework success rate. As a result, I made the following modification on my first cycle: instead of handing the worksheet without any clarification, I would thoroughly explain it and discuss some potential difficulties. Also, I offered my students 3 weekly virtual office hours for more individual assistance. 
Following this strategy, I assigned my students of group A two worksheets. Few students made effective use of the offered office hours but most seemed to lack enthusiasm or were engaged with other lectures at these times. The effects of instruction provided are significantly noticed and the homework completion rates by implementing this method were almost doubled, see Table 5.

Cycle 3:

This strategy was designed to meet the following students' high-level need:

1- to value efforts and get verification feedback.

Action: credit students' work and give simple verification feedback

In all my previous methods, I chose not to collect homework assignments, and not to grade them because I thought many of my students were self-motivated. Students felt that the time they wasted was not valued, as well as, all the efforts they made to solve the problems, and lacked feedback. Previous research on homework effectiveness claims that to be effective the homework should be checked (Paschal, Weinstein, \& Walberg, 1984; Trussell 2003).

Narciss (1999) suggests feedback's role in the learning process is not simply information processing, but a more complex milieu with feedback having an influence on the learner's affective and motivational processes. From a cognitive perspective feedback is regarded as a source of information necessary for verification, elaboration, concept development, and metacognitive adaptation. Kulhavy \& Stock, (1989) defines Verification feedback as a simple determination of the correctness of a response; it is either right or wrong.

Feedback is necessary in both behaviorists learning and cognitive learning. In behaviorist theory, feedback is needed to help learners add the appropriate response. In cognitive theory, feedback is needed to help learners build broad rules or procedures (Mayer, 2003). One form of feedback is grading homework by labeling answers as correct or incorrect (verification feedback) and giving credit points for those correct answers. I thought by following this method, homework may be taken more seriously by students, and therefore their rate of homework completion might increase.

I made a very strong effort to always get homework back before or by the due date, and assigned $10 \%$ of a student's total score on it.

Students of Group A handed two worksheets using this strategy. Grading the homework proved to give the students an incentive to spend the necessary time to complete their assignments. The percentage of homework completion achieved by implementing this strategy was $89.7 \%$ (Table 5).

Cycle 4:

Other very important students' high-level needs are:

1- to integrate technology to communicate with ease;

2- to get appropriate feedback type.

Action: use email as a communication medium and feedback tool

In this study, the usage of virtual office hours by students was noticed to be limited. This traditional approach of face-to-face office hours has also been shown in previous studies to be infrequently used by students, who cite lack of convenience or accessibility as the main 
deterrents (Pascarella 1980; Nadler \& Nadler, 2000). Currently, there is extensive research into the role of feedback in education in classroom. However, there is little research outlining the use of computer-mediated communication (CMC) in higher education outside the classroom. Research has shown the positive benefits of informal student-faculty interaction including higher levels of student satisfaction, retention, and academic performance (Cotton \& Wilson, 2006; Nadler et al., 2000; Wingard, 2004). Researchers have also found support for the benefits of $\mathrm{CMC}$ as a means to facilitate and increase the amount of interaction and communication between students and their professors (Chou 2001; Klassen \& Vogel, 2003). Li, Finley, Pitts, and Guo (2011) reported that students prefer asynchronous tools such as email to communicate with the professor and that these tools can effectively help students in solving problems outside the classroom. Others have noted that students reticent to speak in face-to-face contexts are more willing to participate in the electronic context (Beauvois, 1995; Warschauer, 1995; GonzálezBueno, 1998). Beauvois (1997) reported that CMC increased total class participation to $100 \%$.

Looking at basic communication models, feedback can be seen as a special case of the general communication process in which some sender conveys a message to a recipient (Ilgen, Fisher, \& Taylor, 1979). Email can be a wonderful tool for delivering feedback to students (Huett, 2004). Debard and Guidera (2000) stress that email can increase faculty-student contact resulting in improved student involvement and motivation. They also point to email as a source of more intensive student interaction that can lead to deeper, more active, and more engaged learning.

Based on the results of the above studies, students in group A were offered the opportunity to confer with the instructor outside their classroom by email and guaranteed to be answered within a reasonable amount of time. Email was mainly used by students for their queries and requests for support with their assignments, without having to wait for the next class session. It was also used to give students some elaboration feedback, that is, feedback of the type defined by Kulhavy et al., (1989) "information that guides the learner toward the desired response and can be classified as task-specific, instruction-based, or extra-instructional". To avoid any possible delay in submitting assignments, students were also offered the chance to utilize e-mail as soon as they are finished. Whenever an assignment was received, it was not only graded, but also supported with error correction comments, i.e., "answer feedback" before it was returned.

Students of Group A handed one worksheet using this strategy. About $95 \%$ of the students mastered use of the strategy, and their homework completion rates and the quality of their homework products improved.

A compare and contrast chart of the action research cycles is shown in Table 3 . The timeline of the action research is presented in Figure 3.

\section{Results}

Students of Group B were given six homework assignments (of repetitive type) by following homework policy 1, and two assignments using the strategy of the first cycle of homework policy 2 . The percentages of homework completion associated with these 8 assignments are shown in Table 4. Over a two-month period, an average of only $12 \%$ of these students reported completed their 6 assignments consistently. After the instructor handed the new type of homework through Cycle 1, a significant increase in the rate of homework completion was 
noticed, and a mean percentage of $25.8 \%$ of completed homework was recorded. Cycles 2, 3 and 4 were not implemented with this group because of lack of time.

The study was continued, early in the second semester, with students of group A. As for Group B, their rate of homework completion observed with the first assignment of policy 1 was very low (14.3\%), see Table 5. The new administration of Cycle 1 with this group also revealed some progress, and an average of $26.2 \%$ of homework completion was reported.

Although the completion rate of homework is almost doubled through Cycle 1 with both groups, the portion of students turning in homework remained unsatisfactory. This is because not all students were motivated by the same needs. Therefore, more high-level needs, maybe, have to be met. Results of ATS and ATH, obtained in part one of this research, as well as those of Cycle 1, suggested that students of both groups A and B were comparable. Hence, study results with any of the two groups are expected to be the same as with the other, if it was to be involved in the same study. Going through the remaining Cycles: Cycle 2 to Cycle 4 of homework policy 2, with students of Group A, an increasing trend across trials for most students was noticed, see Figure 4. These results seem to support the positive impact of policy 2 in motivating students to complete their homework.

The significantly high percentage of homework completion of $95.1 \%$ students achieved eventually revealed that they are more willing to do homework when the instructor homework policy fulfills most of their relevant high-level needs including ease of communication with instructors.

Table 3: Cycles of Action Research

\begin{tabular}{|l|l|l|l|l|}
\hline & \multicolumn{1}{|c|}{ Cycle 1 } & Cycle 2 & Cycle 3 & Cycle 4 \\
\hline $\begin{array}{l}\text { Students' } \\
\text { high-level } \\
\text { need(s) to } \\
\text { satisfy }\end{array}$ & $\begin{array}{l}\text { Not to be } \\
\text { overloaded } \\
\text { To have moderate } \\
\text { level of homework } \\
\text { with enough time to } \\
\text { complete } \\
\text { To be directed for } \\
\text { proper selection of } \\
\text { homework problems }\end{array}$ & $\begin{array}{l}\text { - To overcome } \\
\text { homework } \\
\text { challenges }\end{array}$ & $\begin{array}{l}\text { - } \\
\text { To value efforts and } \\
\text { get verification } \\
\text { feedback }\end{array}$ & $\begin{array}{l}\text { - To integrate technology to } \\
\text { communicate with ease } \\
\text { - To get appropriate } \\
\text { feedback type }\end{array}$ \\
\hline Action & $\begin{array}{l}\text { Change type and way of } \\
\text { handing homework }\end{array}$ & $\begin{array}{l}\text { Provide supportive } \\
\text { instructions and } \\
\text { virtual office hours }\end{array}$ & $\begin{array}{l}\text { Credit student's work } \\
\text { and give simple } \\
\text { verification feedback }\end{array}$ & $\begin{array}{l}\text { Use email as a } \\
\text { communication medium and } \\
\text { feedback tool }\end{array}$ \\
\hline $\begin{array}{l}\text { Group(s) } \\
\text { involved }\end{array}$ & A, B & A & A & A \\
\hline
\end{tabular}



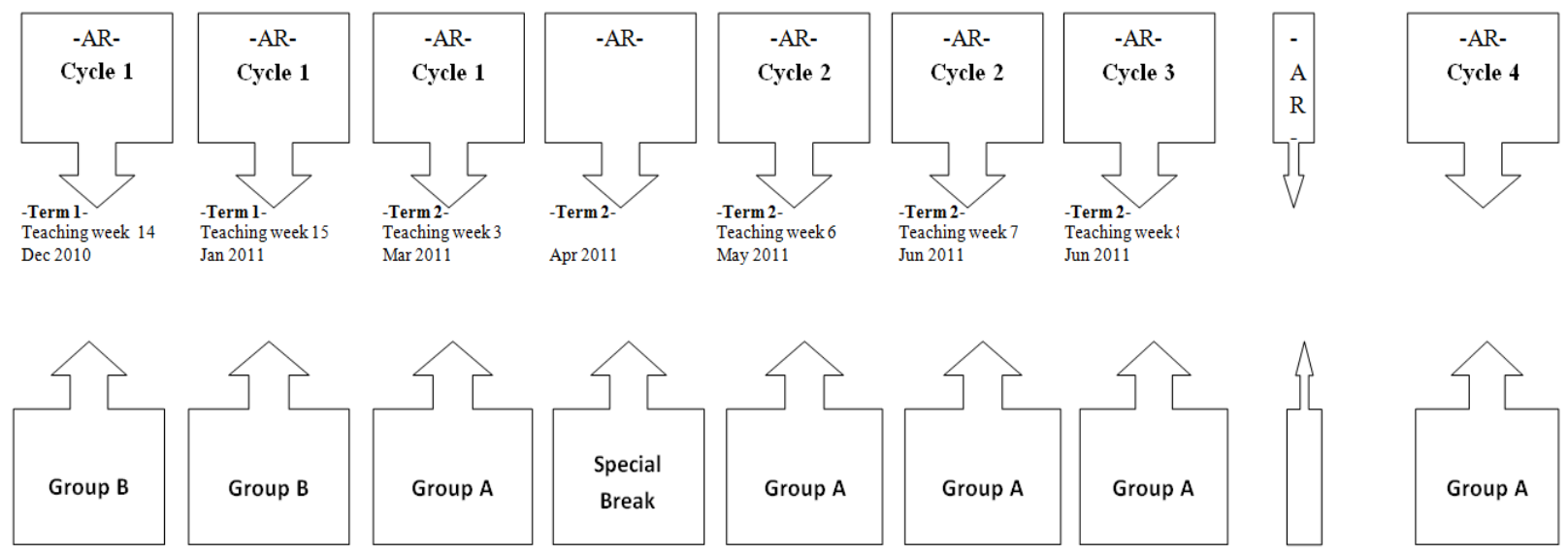

Figure 3

Table 4. Group B percentages of homework completion.

\begin{tabular}{|c|c|c|c|c|c|c|c|}
\hline \multicolumn{7}{|c|}{ Group B } \\
\hline HW1-P1 & HW2-P1 & HW3-P1 & HW4-P1 & HW5-P1 & HW6-P1 & HW7-C1 & HW8-C1 \\
\hline $10.3 \%$ & $13.8 \%$ & $6.9 \%$ & $17.2 \%$ & $10.3 \%$ & $13.8 \%$ & $27.6 \%$ & $24.1 \%$ \\
\hline
\end{tabular}

Table 5. Group A percentages of homework completion.

\begin{tabular}{|c|c|c|c|c|c|c|c|}
\hline \multicolumn{7}{|c|}{ Group A } \\
\hline HW1-P1 & HW2-C1 & HW3-C1 & HW4-C2 & HW5-C2 & HW6-C3 & HW7-C3 & HW8-C4 \\
\hline $14.3 \%$ & $23.8 \%$ & $28.6 \%$ & $57.14 \%$ & $52.38 \%$ & $69.0 \%$ & $89.7 \%$ & $95.1 \%$ \\
\hline
\end{tabular}




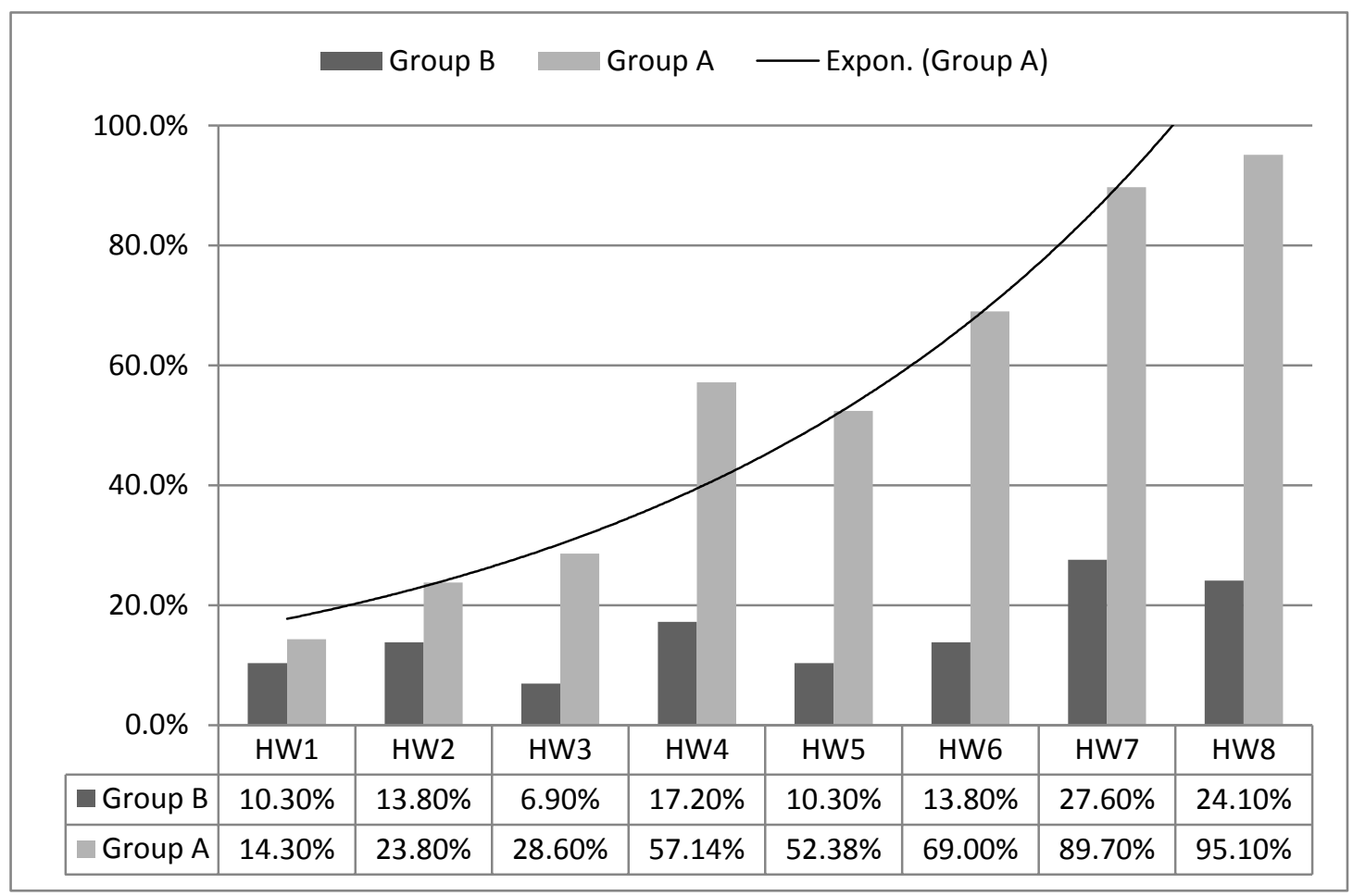

Figure 4. Percentages of homework completed by groups $A$ and $B$.

\section{Discussion}

The first part of our research reveals that undergraduate engineering students involved in an introductory statistics course may have positive but weak attitudes toward Statistics, and also similar attitudes toward course homework.

The significant relationship between students' attitudes toward homework and their attitudes toward statistics, as was also revealed by $\mathrm{Xu}$ (2005), suggests that instructors should work to achieve homework policies that can motivate students by fulfilling most of their relevant high-level needs such as having: concrete assignments at moderate levels with some supporting instructions, appropriate amount of homework and time, appropriate feedback type, and positive consequences for homework completion. The findings also showed that students offered with asynchronous communication by email reported higher communication interaction. Most of these aspects are within an instructor control, e.g., length, type of assignments, assessment methods, and integrating technology such as email can be all manipulated.

It is clear that when elaboration feedback is received in a timely manner, it is more effective than the simple verification feedback. This would agree with (Bangert-Drowns, Kulik, \& Morgan, 1991) study. Also, involving students in technology by using email as a communication and feedback tool can increase 
and speed up student participation. This is in line with the research of Huett (2004) who stated that "The successful use of email in the educational arena will be largely determined by how well it meets the identified needs of the learner".

It could be useful for statistics instructors to allocate sometime at the beginning of each term to assess their students' attitudes, especially those enrolled in introductory statistics courses, and based on their findings design the appropriate homework policy for their students.

The results of this study are certainly a positive demonstration with regard to what homework policies that are carefully designed and applied to meet students' high-level needs relevant to homework can do. This was evident in the significant differences in portions of homework completed by students of both Groups A and B.

\section{Acknowledgments}

We would like to thank Dr. Adrian Brockett and Dr. Catherine Samiei, York St John University, for their helpful discussion on an earlier report of this work.

\section{References}

Aldogan, A., \& Aseeri, A. (2003), Psychometric Characteristics of the Attitude Towards Statistics Scale, Umm Al-Qura University Journal of Educational and Social Sciences and Humanities, 15(2), 99-114.

Anderman, L. H., \& Midgley, C. (1998), Motivation and middle school students [ERIC digest]. Champaign, IL: ERIC Clearinghouse on Elementary and Early Childhood Education. Retrieved June 25, 2002. Available at http://www.ed.gov/databases/ERIC_Digests/ed421281.html

Bangert-Drowns, R. L., Kulik, J. A., and Morgan, M. (1991), The instructional effects of feedback in testlike events, Review of Educational Research, 61(2), 213-238.

Beauvois, M. H. (1995), E-Talk: Attitudes and Motivation in Computer-Assisted Classroom Discussion, Computers and the Humanities 28, 177-190.

Beauvois, M. H. (1997), Computer-Mediated Communication (CMC): Technology for TechnologyEnhanced Language Learning, Lincolnwood, IL: National Textbook Company, 165-184.

Biehler, R. F. and Snowman, J. (1986), Psychology Applied to Teaching (5 ${ }^{\text {th }}$ Ed.) Boston: Houghton Mifflin Company.

Bempechat, J. (2004), The Motivational Benefits of Homework: A Social-Cognitive Perspective, Theory Into Practice, 43(3), 189-196.

Chou, C. (2001), Formative Evaluation of Synchronous CMC Systems for a Learner-Centered Online Course, Journal of Interactive Learning Research, 12(2/3), 169-188.

Cooper, H. (1994), Homework Research and Policy: A Review of Literature. Available at

http://www.education.umn.edu/CAREI/Reports/Rpractice/Summer94/homework.html

Cooper, H. (2001). The battle over homework. California: Corwin Press.

Cooper, H., Lindsey, J. J., Nye, B., \& Greathouse, S. (1998), Relationships among attitudes about homework assigned and completed, and student achievement, Journal of Educational Psychology, 90, 70-83.

Cotton, S., \& Wilson, B. (2006), Student-faculty Interactions: Dynamics and Determinants, Higher Education, 51(4), 487-519.

DeBard, R., \& Guidera, S. (2000), Adapting asynchronous communication to meet the seven principles of effective teaching, Journal of Educational Technology Systems, 28(3), 219-239.

Dewey, J. (1933). How We Think: A Restatement of the Relation of Reflective Thinking to the Educative Process, Boston: D.C. Heath

Emmioğlu, E., \& Capa-Aydin, Y. (2012), Attitudes and achievement in statistics: A meta-analysis study, Statistics Education Research Journal, 11(2), 95-102. 
Erickson, S. C. (1978), The Lecture. Memo to the Faculty, no. 60. Ann Arbor: Center for Research on Teaching and Learning, University of Michigan.

Gal, I., \& Ginsburg, L. (1994), The Role of Beliefs and Attitudes in Learning Statistics: Towards an Assessment Framework, Journal of Statistics Education, 2(2).

Gal, I., Ginsburg, L., \& Scau, C. (1997), Monitoring attitudes and beliefs in statistics education, The Assessment Challenge in Statistics Education, eds. I. Gal and J. B. Garfield, Amsterdam: IOS Press, 37-51.

González-Bueno, M. (1998), The effects of electronic mail on Spanish L2 discourse, Language Learning \& Technology 1(2), 55-70.

Griffth, J., Adams, L., Gu, L., Hart, C., \& Nichols-Whitehead, P. (2012), Students attitudes toward statistics across the disciplines: A mixed-methods approach, Statistics Education Research Journal, 11(2), 45-46.

Harvey, A. L., Plake, B. S., \& Wise, S. L. (1985), The validity of six beliefs about factors related to statistics achievement, Paper presented at the annual meeting of the American Educational Research Association, Chicago, IL. (ERIC Document Reproduction Service No. ED262 965).

Herzberg, F. (1966), The work and the nature of man, Cleveland, OH: The World Publishing Company.

Hopkins, D. (1985), A teacher's guide to classroom research, Philadelphia: Open University Press.

Huett, J. (2004), Email as an Educational Feedback Tool: Relative Advantages and Implementation Guidelines, International Journal of Instructional Technology \& Distance learning, 1(6), 35-44.

Ilgen, D. R., Fisher, C. D., \& Taylor, M. S. (1979), Consequences of individual feedback on behavior in organizations, Journal of Applied Psychology, 64, 349-371.

Keys, W., Harris, S., \& Fernandes, C. (1997), Third International Mathematics and Science Study, Second National Report. Part 2: Patterns of Mathematics and Science Teaching in Upper Primary Schools in England and Eight Other Counties. Slough: NFER.

Klassen, J., \& Vogel, D. (2003), Ethical Issues Arising in e-Education, Web-Based Teaching: Learning from Experience, A. K. Aggarwal (ed), University of Baltimore Press, Baltimore.

Kottke, J. L. (2000), Mathematical proficiency, statistics knowledge, attitudes toward statistics, and measurement course performance, College Student Journal, 34(3), 334-347.

Kulhavy, R. W., \& Stock, W. A. (1989), Feedback in written instruction: The place of response certitude, Educational Psychology Review, 1(4), 279-308.

Li, L., Finley, J., Pitts, J., \& Guo, R. (2011), Which is a better choice for student-faculty interaction: synchronous or asynchronous communication? Journal of Technology Research, 2, 1-12.

Marzano, R. J., Pickering, D. J., \& Pollock, J. E. (2001), Classroom Instruction That Works; ResearchBased Strategies for Increasing Student Achievement, Association for Supervision and Curriculum Development, USA.

Maslow, A. H. (1943), A Theory of Human Motivation, Psychological Review, 50, 370-396.

Mayer, R. E. (2003), Learning and Instruction, Merrill Prentice Hall, Upper Saddle River, New Jersey.

Mvududu, N. (2003), A Cross-cultural study of the connection between students' attitudes toward statistics and the use of constructivist strategies in the course, Journal of Statistics Education, 11(3).

Nadler, M. K., \& Nadler, L. B. (2000), Out-of-Class Communications Between Faculty and Students: A Faculty Perspective, Communication Studies, 51(2), 176-188.

Narciss, S. (1999), Motivational effects of the in formativeness of feedback, Paper presented at the annual meeting of the American Educational Research Association, Montreal, Quebec, Canada.

Nolan, M., Beran, T., \& Hecker, K. (2012), Surveys assessing students' attitudes toward statistics: A systematic review of validity and reliability, Statistics Education Research Journal, 11(2), 103-123.

Onwuegbuzie, A. J., \& Daley, C. (1999), Perfectionism and statistics anxiety, Personality \& Individual Differences, 266, 1089-1102.

Ostler, E. (1997), The effect of learning mathematics reading strategies on secondary students' homework grades, The Clearing House, 77 (1), 37-41. 
Paschal, R. A., Weinstein, T., \& Walberg, H. J. (1984), The effects of homework on learning: A quantitative synthesis, Journal of Educational Research, 78(2), 97-104.

Pascarella, E. T. (1980), Student-Faculty Informal Contact and College Outcomes, Review of Educational Research, 50, 545-595.

Ramirez, C., Schau, C., \& Emmioğlu, E. (2012), The importance of attitudes in statistics education, Statistics Education Research Journal, 11(2), 57-71.

Rhoads, T. R., \& Hubele, N. F. (2000), Students attitudes toward statistics before and after a computerintegrated introductory statistics course. IEEE Transactions on Education, 43(2), 182-187.

Roberts, D. M., \& Bilderback, E. W. (1980), Reliability and validity of a statistics attitude survey, Education and Psychological Measurement, 40, 235-238.

Roberts, D. M., \& Saxe, J. E. (1982), Validity of Statistics Attitude Survey: A Follow-Up Study, Educational and Psychological Measurement, 42, 907-912.

Schau, C., Stevens, J., Dauphinee, T. L., \& Del Vecchio, A. (1995), The development and validation of the Survey of Attitudes Toward Statistics, Educational and Psychological Measurement, 55(5), 868875.

Sorge, C., \& Schau, C. (2002), Impact of Engineering Students' Attitudes on Achievement in Statistics: A Structural Model, Paper presented at the Annual meeting of the American Educational Research Association (New Orleans, April, 2002).

Trussell, H. J. (2003), A Study of the Effect of Graded Homework in a Preparatory Math Course for Electrical Engineers, Journal of Engineering Education, 92(2), 141-146.

Vanhoof, S., Sotos, A., Onghena, P., Verschaffel, L., Van Dooren, W., \& Van den Noortgate, W. (2006), Attitudes toward statistics and their relationship with short-and long term exam results, Journal of Statistics Education, 14(3).

$\mathrm{Xu}$, J. (2005), Homework attitudes and management strategies, Academic Exchange Quarterly, 9(4), 239243.

Warschauer, M. (1995), Comparing face-to-face and electronic discussion in the second language classroom, CALICO Journal, 13(2 \&3), 7-26.

Wingard, R. (2004), Classroom Teaching Changes in Web-Enhanced Courses: A Multi-Institutional Study, EDUCAUSE Quarterly, 27(1).

Wise, S. L. (1985), The development and validation of a scale measuring attitudes toward statistics, Educational and Psychological Measurement, 45, 401-405. [ATS available Online: http://bit.ly/Tl3ATj] 